RESEARCH ARTICLE

\title{
Handymen, Hippies and Healing: Social Transformation through the DIY Movement (1940s to 1970s) in North America
}

\author{
Cathy D. Smith*
}

This paper explores the relation between the 'DIY' ('do-it-yourself') movement and 'DIY architecture', and the notion of social transformation, in examples of DIY manuals and discourse of North America drawn from the 1940s to the 1970s. The DIY movement emerged as a significant phenomenon in North America of the 1950s, where it was associated with a mainstream audience and a residential market. By the 1960s, the DIY approach was embraced by the North American counterculture as a self-sustaining sensibility that could overcome a reliance on the mainstream, consumerist society that spurned it. On the surface, the association of DIY with the counterculture and countercultural architects appears to denote a significant ideological shift from its original association with the beliefs and culture of mainstream North America and the nuclear family. However, one of the key characterisations of the DIY movement identified in the present paper is the way it is bound to the notion of social identity and transformation, regardless of ideology. Particular attention is paid to DIY manuals and discourse of the 1950s.

\section{Introduction}

There is much renewed interest in the radical social and political agendas of architects associated with the North American counterculture of the 1960s and 1970s, including the discourse and publications of this fertile period. ${ }^{1}$ The countercultural DIY (do-it-yourself) manual was an important educational platform through which counterculturalists could disseminate not only practical knowhow of construction and technology, but also the philosophical and cultural ethos of the movement-a direct challenge to mainstream American values and lifestyles (Smith 2012: 9). Countercultural manuals and catalogues such as the Whole Earth Catalog (WEC) are understood to be radical departures from the standard commercial catalogue because of their strong ideological and social agendas, as well as their anti-consumerist stance. These manuals included 'how-to' information on a variety of topics and types of small-scale projects, including housing. The countercultural DIY manual has an interesting, though under-examined, relation to its forebears: the catalogues and manuals of mainstream 1940s and 1950s North America. It is the contention of the present paper that the countercultural DIY manual was merely an extension of, rather than a departure from, the notion of social transformation embedded in the earlier American DIY manuals produced in the period after the Great Depression. These earlier DIY manuals were already associated with social

\footnotetext{
* University of Newcastle, Australia Cathy.D.Smith@newcastle.edu.au
}

and ideological agendas, albeit with a different focus to that of the counterculture. A more detailed exploration of specific DIY manuals from the 1940s and 1950s and of the discourses in which they participate reveals that the construction of the family home and its interiors was seen to involve the simultaneous construction of both the individual self and the nuclear family unit.

The notions of identity and transformation invoked in the manuals and discourse are associated with two phases of the North American DIY movement in the decades following the Great Depression. The first phase includes DIY manuals of the early 1940s and 1950s; the second includes the countercultural manuals of the 1960s and 1970s. A comparison of the two phases reinforces the idea that regardless of the social and ideological differences with which these two time periods are imbued, there remains a discernible link between the DIY approach and social transformation in North America. The manuals from the early phase as well as some of the later countercultural manuals referred to here focus on small-scale residential DIY projects. ${ }^{2}$ Despite this focus, the transformation of the private residential interior inflects social identity and status outside of the home.

The earlier manuals and discourse, especially from the 1950s, form the context for a deeper interrogation of the under-theorised area of early DIY. There are few academic analyses of the DIY movement from this early period; nor are there any investigations of the relation between the earlier and later countercultural incarnations of the DIY manual. The manuals from both time frames discussed here are selected for the way they connect social 
transformation (individual or collective) to DIY practices: they contain instructional images and guidelines to inspire their readers to build projects themselves, alongside justifications for the social and psychological benefits of 'doing-it-yourself'. Postwar period articles were also written about the DIY phenomenon, including a Time article in 1954 and an essay written by Albert Roland of the United States Information Agency in 1958. According to historian Steven Gelber, Roland was 'the only academic analyst of do-it-yourself in the 1950s' (Gelber 1999: 292). Both articles were published during the period in which the DIY phenomenon emerged in North America, and reinforce the idea that, from its inception, DIY was associated with individual and collective social transformation-even within the conservative framework of postwar America. It is not possible to evaluate whether DIY action or the manuals themselves actually prompted transformations within its readership; such changes are too complex. Rather, the focus is on the way in which the DIY manuals themselves serve to connect the notion of social transformation to DIY practices.

\section{DIY and the self}

As a distinct term and phenomenon, DIY emerged in North America at the end of World War Two. Its evolution can be traced to the earlier popularity of making and craft during the Victorian era in both Britain and America. Along with Steven Gelber, historian Carolyn Goldstein-author of a text devoted to North American DIY-also associates the practice with the renewed interest in making and craft that was fostered by the American Arts and Crafts movement at the turn of the twentieth century (Gelber 1999: 195; Goldstein 1998: 17). Gelber suggests a broad definition of DIY through an analysis of the phenomenon of hobbies involving 'productive leisure', particularly in the North America of the 1950s (Gelber 1999: 6). He defines DIY 'quite literally as anything that people did for themselves' (Gelber 1999: 283). In 1954, Time magazine proclaimed that 'doing-it-yourself' was '[t]he new billion-dollar hobby' in North America (Time 1954: 46). The article makes reference to 'hobbyists', to 'do-it-yourselfers' and even to a DIY 'retired architect' (Time 1954: 46, 51, 47). Although the Time article was one of the first significant publications to recognise and name DIY as a phenomenon, the term had been used earlier in a 1912 article by Garrett Winslow for Suburban Life magazine, entitled 'Practical Decoration for the Home Interior' (Gelber 1999: 66). ${ }^{3}$ Suburban Life encouraged home owners to paint their houses themselves rather than hire professional painters. Prior to Winslow's use of the term 'DIY', an interest in hands-on home improvement and manual skills had begun much earlier in America during the late 1800s, encouraged by the expanding mass publication market for how-to publications (Gelber 1999: 67; Goldstein 1998: 16-17); ' [b]y the 1930s, do-it-yourself had become a category embracing all household jobs requiring the use of tools' (Gelber 1999: 89). DIY might be associated with British and European antecedents, but Goldstein argues that the phenomenon as we know it today came to be most closely associated with North America in the years following World War Two, an era she describes as the 'Age of Do-It-Yourself' (Goldstein 1998: 21).

Fifty Things to Make for the Home (1941), by Julian Starr, is a North American how-to manual published just as the United States entered World War Two. While the text is not explicitly described as DIY (in the manner coined by Winslow), a brief exploration of this text and its suggested audience establishes the context and arguments for the then-emerging DIY phenomenon and attendant discourse, particularly the association of individual well-being with self-directed production. Fifty Things to Make for the Home is a how-to manual published as a follow-on to the book Make It Yourself, the title of a weekly newspaper column in which Starr's texts first appeared (Starr 1941: vi). It is specifically aimed at an audience of home-based 'craftsmen' and homeowners. The text focuses on the construction of household items and furniture using, in most cases, common hand-tools and 'raw' materials (particularly timber). As is typical of how-to publications of the time, and DIY manuals more broadly, the text is organised according to specific categories and types of projects, including 'Kitchen Accessories and Improvements', 'Toys and Play Equipment', and 'Novelties' (Starr 1941: vii-ix). An additional section titled 'The Workshop' outlines both pragmatic information and the rationale for setting up a home workshop. This section begins with a chapter whose title encompasses Starr's belief in DIY pursuit: 'The Value of a Home Workshop: Its Recreational Value Outweighs All Other Considerations' (Starr 1941: 3). In this chapter, the home workshop is associated with health and psychological transformation. Starr passionately declares that as 'one progresses in the use of tools, the basement workshop will become a place of refuge, a source of rejuvenation for a spirit bewildered or worn by the vicissitudes of ordinary existence' (Starr 1941: 5). Self-directed making within the home workshop is presented as a productive psychological release from the challenges of office-bound, intellectual employment: '[m]any think the transition from work to play should be physical. Psychologists know that it must also be mental. And that's where the home workshop comes in' (Starr 1941: 4). Starr also suggests that while the products of do-it-yourself labour might be economically justifiable, the emotional investment and sense of self-satisfaction involved in creating a beautiful object is ultimately a more important consideration (Starr 1941: 4). With this in mind, he declares that men should retain their home workshops at all costs: "[i]f a man has the slightest inclination toward a hammer and saw he should resist all dulcet-toned suggestions that he surrender his basement or any considerable portion of it to a "rumpus room"' (Starr 1941: 3).

Apart from the initial arguments for home workshops and self-production, subsequent chapters are dedicated to the construction of household objects and furniture (both built-in and freestanding). The manual's format is consistent throughout the text: each DIY item is typically accompanied by a three-dimensional drawing, plans 
and elevations (not to scale), or a combination thereof; and is allocated a number and title, often with a quirky byline. For example, item 54 in the 'Novelties' section is titled 'Individual Guest Trays: Save Table Tops and Guests' Feelings with These Little Trays' (Starr 1941: 195). The main text then describes how guest trays can save visitors from potential drink-spill embarrassments. Aside from this observation, the descriptive text that follows is focused on materials and techniques that are interspersed with personal advice, such as, "[m]y preference is for walnut, given a light stain' (Starr 1941: 197). An unusual item in the 'Furniture' section is the 'Military Field Table', which is described as 'A Compact Folding Table for Campers and Soldiers' (Starr 1941: 114), and is perhaps to be expected within the context of America's impending involvement in World War Two. Another interesting item is the reinforced and extremely large 'Portable Icebox for the Beach' which-somewhat misleadingly-refers to the 2-inch think galvanised steel and ply walls as being 'light weight' (Starr 1941: 182). A final unique example involves the reconfiguration of a salad bowl into a 'Three Legged Knitting Bowl'. Starr gives the following advice for starting this repurposing project using an existing bowl of suitable material and scale, which, in doing so, reinforces the connections between the processes involved in cooking and do-it-yourself activity:

The formula for making the knitting bowl shown in the accompanying illustration should begin like the time-honored recipe for rabbit stew-'First you catch the rabbit.' The rabbit in this case is a good salad bowl, at least 14 inches in diameter, which has been turned from a well-seasoned hardwood butt, and which is clear of imperfections that might cause it to split. (Starr 1941: 205)

Taking the analogy of cooking and recipes further, Starr suggests that the text is intended to prompt and guide readers who will inevitably customise and individualise their projects. The readers, therefore, were invited to 'take the general ideas, work them out to suit themselves, and write long letters explaining what they have achieved' (Starr 1941: vi). At its time of writing, the readership of Fifty Things to Make for the Home comprised budding North American craftspeople and home owners seeking to enhance both home and self (Starr 1941: v-vi). A few years later, the discourse on DIY and making shifted in focus from the individual maker to the nuclear family. From the later months of 1951 to January 1952, New York's Museum of Modern Art (MOMA) maintained a woodworking workshop in its 'People's Art Center'. The People's Art Center provided art and craft classes for 'amateurs', including 'men, women and children' (The Museum of Modern Art 1951: 1). Classes were run in studios and workshops located in MOMA's annex, the Grace Rainey Rogers Memorial in West $53^{\text {rd }}$ Street. The woodworking course was specifically introduced for 'fathers and sons aged 11 to 14' (The Museum of Modern Art 1951: 2). In a 1951 media release, MOMA implied that the woodworking course provided father-son bonding opportunities through DIY projects for use in the home: 'fathers and sons will work together making toys, games, and simple woodworking projects such as table lamps, art easels, silver chests and hanging shelves' (The Museum of Modern Art 1951: 2). The course was part of the Center's broader purpose and focus which was, in the words of the director Victor D'Amico, 'the individual's need for self-expression' (The Museum of Modern Art 1951: 2). An article in the New York Times in 1952 noted that the woodworking workshop provided opportunities for apartment-dwelling fathers and sons to connect through DIY in the same way that their 'suburban counterparts' might bond in their home garage workshop (Gelber 1999: 290). The MOMA example is particularly interesting as it relocates familial-based DIY and its attendant roles into the public domain. 'Selfexpression' through woodworking appears to be part of an important social ambition: the crafting of father-son relations. There is no mention of the equivalent activities for women and girls, other than the Center's aforementioned mission to generally involve women and children as well as men.

A few years later, an article in House Beautiful suggested that the DIY audience had shifted from the budding 'craftsperson' and home handyman to more socially aspiring 'homeowners' who achieve a sense of self-satisfaction from their DIY pursuits. When the House Beautiful magazine published the article 'What not to do yourself' in July 1954 (a month before the aforementioned piece in Time), it also signalled the increasing popularity of this post-war movement in North America. This pragmatically focused article recognises the popularity of DIY while warning potential do-it-yourselfers of the dangers in doing it yourself' (House Beautiful 1954: 54). The article positions DIY as part of a holistic and more independent lifestyle:

For millions of homeowners, do-it-yourself has proved to be a wonderful new way of life. It results in getting done what they want when they wantand just the way they want it done. There's nothing so beautiful as something you've made yourself. (House Beautiful 1954: 54)

\section{DIY and wellbeing}

Although the aforementioned texts by Starr and in House Beautiful associate DIY activities with a sense of inner satisfaction, the Time article makes a more direct and emphatic connection between DIY pursuit, social identity and well-being. According to Time, the DIY impulse is associated with the American male psyche: that 'millions find joy in building is nothing new. Men have puttered around since the dawn of time [...]. And Americans more than other people, have always been a nation of howtoers, of putterers, tinkerers and inventors' (Time 1954: 49). DIY is not, however, limited to the American 'menfolk', even if the nature and focus of women's DIY is different. Indeed, Time refers to economic data indicating that, in 1953, 'Do It Herself' had a significant impact on the economy: 'while the menfolk labored mightily, 35 million 
U.S. women made their own clothes (using 750 million yds. of cloth), gave themselves 32 million home permanents, leafed through millions of copies of do-it-yourself magazines and books, looking for still more projects for their husbands and themselves' (Time 1954: 46).

Even though the Time article suggests that DIY can be an economic alternative to hiring skilled tradespeople, the extraordinary popularity of the phenomenon is ultimately attributed to its perceived psychological and therapeutic benefits (Time 1954: 46). The article suggests that do-ityourselfers have supplanted the role of the 'indispensable handyman' because the DIY pursuit is rewarding: 'millions of amateur hobbyists [...] do all his work-and much more-and find it wonderful fun' (Time 1954: 46). Several references are made to the health benefits of DIY with supporting anecdotes from the medical profession: '[o]ne Dallas doctor, a do-it-yourself addict himself, often advises patients to "go home and start doing things themselves"' (Time 1954: 47). Indeed, DIY was perceived by some doit-yourselfers to be a preventive for suicide and 'nervous breakdown' (Time 1954: 47-48). This leads to the characterisation of DIY as 'Good Medicine' (Time 1954: 47). In contrast to the overspecialised American workplace of the 1950s, DIY activities allowed individuals to initiate and be involved in all stages of a project, directly observing how their work formed part of a meaningful accomplishment in its entirety. The healing and medicinal power of DIY also relates to the redirection of a 'patients' psychological energies into manual labour and productive output. Thus, 'in his home workshop, anyone from president down to file clerk can take satisfaction from the fine table, chair or cabinet taking shape under his own hands-and bulge with pride again as he shows them off to friends' (Time 1954: 47). Nevertheless, for those do-it-yourselfers who exceed their capacity to complete a project, DIY can be detrimental to individual health, particularly for the wife of 'one enthusiast' retrofitting an attic who was inadvertently (though temporarily) sealed into the wall cavity by her husband (Time 1954: 48). Americans wanting to improve their limited skillset might attend one of the many DIY clinics offered by local hardware stores (Time 1954: 49). The term 'clinic' is itself noteworthy as an additional confirmation of the therapeutic value of DIY. Moreover, the do-it-yourselfer of 1954 could analyse and reconstruct both self and home by referring to to the many and varied DIY publications then available: 'in New York City's public library, there are 3,500 how-to books [...] There are dozens of books on How to Buy a House and how to make it better. There is even one on How to Make Sense' (Time 1954: 46).

\section{Self-actualisation of the individual and family}

The development of self-worth and social identity through DIY is an important point for Roland of the United States Information Agency, a postwar federal government agency that promoted national issues for the duration of its existence (1953 to 1999). In 1958, Roland published an essay on DIY in which he associated the creative aspects of DIY with psychological health and transformation, alongside the formation of social identity. Roland's article is significant not only because it was published at the height of the DIY 'boom' in 1950s North America, but because DIY is defined as symptomatic of an individual need for selfactualisation. Roland attributes the popularity of the DIY phenomenon to the 'relation of do-it-yourself to society as a whole' (Roland 1958: 163). For Roland, self-identity can be produced alongside, and through, direct interactions with the material world. He states that the 'business of dealing with things, of creating something, is obviously a very important aspect of craftsmanship, and of the do-ityourself trend as a whole' (Roland 1958: 158).

Although Roland concentrates on examples of DIY within the home, he speaks of the issue of self-transformation in broader societal terms. DIY of the 1950s was seen to satisfy a diverse range of inner motivations and outwardly focused goals. Echoing Starr's 1941 sentiment of the basement workshop being a 'refuge' (Starr 1941: 5), Roland refers to the writings of the American writer Henry Thoreau and the notion of self-individuation invoked in Walden, his 1854 memoire describing the construction of his self-built rural cabin of the same name. Roland relates Thoreau's withdrawal from society to the sense of refuge from everyday work pressures afforded within the homegarage workshop. Roland's reference to the workshop as a refuge also resonates with the aforementioned perceived therapeutic benefits of DIY (Starr 1941: 5; Time 1954: 47-48). He argued that men could withdraw 'to their basement and garage workshops to find there a temporary Walden' (Roland 1958: 154). The freedom to produce outside of the confines of everyday social expectation contributed, Roland says, to the formation of the individual self because DIY is active, it is specific, it equips each of them to feel individually more competent and thus helps assert personal identity' (Roland 1958: 164). Indeed, the home workshop provides do-it-yourselfers with a 'touchstone for evaluating life around them-and their own' (Roland 1958: 155).

It is important to note, however, that Roland did not regard DIY as a uniform practice. Its capacity to inform the formation of identity was for him highly dependent on psychological motivations that would vary from one do-it-yourselfer to the next (Roland 1958: 157). As noted by Roland himself, individual psychological motivation is difficult to pinpoint with any precision: 'if you try to understand the motivations behind do-it-yourself, it begins to appear as if it were many things to many people' (Roland 1958: 155). Even though it is difficult to discern individual motives, he still argues that these may produce varying degrees of self-actualisation. For example, he suggests that for some do-it-yourselfers, the primary motivation is acquisition and consumption rather than self-satisfaction alone (Roland 1958: 155). DIY products and tools and how-to magazines may 'eliminate the need for long practice and the learning of complicated skills' (Roland 1958: 159). In the latter example, Roland sees DIY pursuits are motivated by outcome and lifestyle ambitions rather than by a desire to develop a deeper sense of inner satisfaction: 
For the oldtime craftsman [...] the greatest source of satisfaction is in doing. In Time's words, it stems 'from the fine table, chair or cabinet taking shape under his own hands'. But for today's average craftsman-hobbyist, the main object seems to be to have done. Kit assembly is the extreme example of this. (Roland 1958:159) ${ }^{4}$

Roland seems to be particularly suspicious of do-it-yourselfers motivated by consumerism since it interferes, in his mind, with a more important ambition: individual self-actualisation and transformation. Accordingly, much of his essay-and indeed the early discourse from this period-associates the DIY phenomenon with the sense of inner accomplishment afforded through the mastery of skills and the act of making. In this context, DIY is held to create a deep sense of self-worth and may offer positive psychological release for individuals 'bewildered or worn by the vicissitudes of ordinary existence' (Starr 1941: 5).

While Roland's focus appears to be on DIY as a strategy for the construction of individual identity, the theme of self-actualisation through DIY appears in another wellknown publication associated with the transformation and maintenance of the nuclear family. The 1961 edition of a decorating manual produced by Better Homes \& Gardens-titled the Better Homes and Gardens Decorating Book and originally published in 1956-outlines a number of decorating tips and techniques. Decorating is understood to be part of the creation of an ideal home supporting and indeed producing the family unit and its attendant lifestyle. Even though the manual generally describes practical decorating suggestions, these are positioned within the context of comprehensive social aspirations:

Redecorating makes your dreams come true. It's easy to decorate when you follow the simple 'howto' steps in this book. The following pages show you just how other families like yours achieved the homes of their dreams. (Better Homes and Gardens 1961: 148)

To help readers transform their houses into "dreamhomes", the manual is organised according to different topics, including color schemes, furniture and accessories. Individual pages are hole-punched and held together in a custom-fabricated Better Homes and Gardens ring binder (fig. 1). Chapters are separated by yellow cardboard tabs showing illustrations of happy couples and families rearranging rooms (Better Homes and Gardens 1961: chapter interleafs). Each individual page incorporates both words and imagery-including three-dimensional drawings, plan diagrams and hand-tinted colour photographs. The final 'Index' section includes a scaled planning grid and cut-out furniture templates. Focus is on interior layouts and furnishings, with some reference to adjacent patios and garden spaces (Better Homes and Gardens 1961: 122-123; 352). While the Better Homes and Gardens regular monthly magazine included specific information on retailers and products, the Better Homes and Gardens Dec-

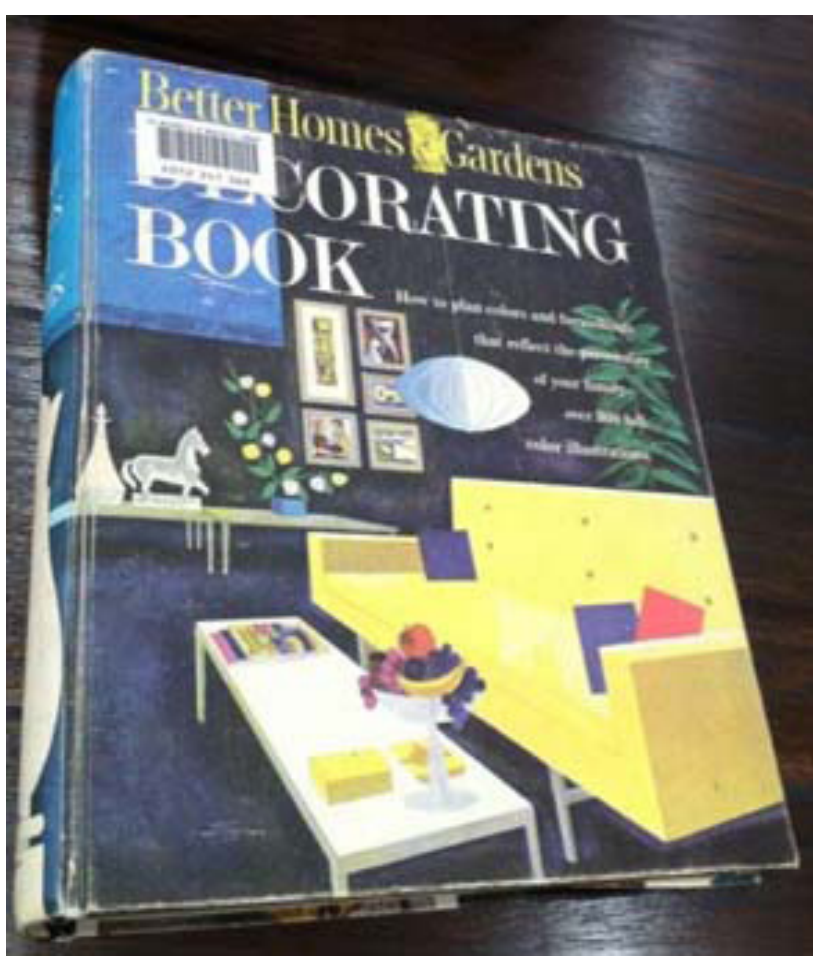

Fig. 1: The 1961 Better Homes and Gardens Decorating Book consisted of loose-leaf inserts within a customised binder for easy updating and replacement. Photograph by the author, 2013.

orating Book neither advocates for nor advertises specific products or manufacturers.

Chapter 1 encourages readers to identify a connection between the character of their family and their décor according to three stylistic categorisations: 'choose among Colonial, Traditional, Contemporary-or mix your styles' (Better Homes and Gardens 1961: 4). Chapter 4, 'Furniture Arrangement', describes the decorating processes and lifestyle ambitions of four hypothetical and aspirational families; the Greens, the Whites, the Smiths, and the Browns. 'The Smiths look for comfort, informality in Smart Contemporary Design' (Better Homes and Gardens 1961: 148); whereas the Browns also 'favour Contemporary Architecture', but plan to move in the future as their young family expands (Better Homes and Gardens 1961: 154). There is reference to the more utilitarian and practical aspects of plan layout (including room 'traffic pattern' analysis), but most suggestions for decorating style are interconnected with lifestyle and social ambitions for the family unit. Thus, '[n]o matter how luxurious your home, or how simple: how gadabout your pattern of living, or how sedentary; how varied your tastes-it's easy to plan colours and furnishings that fit your family's living pattern' (Better Homes and Gardens 1961: 20).

Some sections of the Better Homes and Gardens Decorating Book more overtly reinforce and extend stereotypes for the social roles of different family members, expressed through room layout and decorating style. The section dedicated to a high school girl's room presents a simplistic and arguably superficial account of a girl's life and the attendant environmental needs for organisation 
and containment: '[y]oung girls need room for primping, study, and guests [...] To keep them happy-and the rest of the family sane-provide a spot of their own where all of these activities can go on undisturbed and without disturbing' (Better Homes and Gardens 1961: 328). Girls and boys are both aesthetically typecast: ' [f]rilly curtains, a dressing table, soft pastels-and presto, it's a young lady's room. Change to simple, rough-textured fabrics, deep tones, and you have a young man's room' (Better Homes and Gardens 1961: 327). The manual also addresses the reader as if she were assumed to be both female and married: 'Do you need a quiet spot to sit down with your husband at the end of the day? Plan a lounge grouping in the dining room or kitchen' (Better Homes \& Gardens 1961: 342). However restrictive and conformist these social categories may be, the manual conveyed a sense that social identity could be assembled alongside and through the construction of interior décor.

The Better Homes and Gardens Decorating Book contains continuous references to the identity and formation of the nuclear family according to suggested lifestyles and value systems. Nevertheless, both the format and content of the manual somewhat paradoxically encouraged individual expression and interpretation. The loose-leaf, ring-binder format of the manual facilitates easy updating in the manner of an expanding cookbook. Readers could also customise and transform the binder's contents according to their own tastes-adding notes or additional pages from the monthly magazine-in the same way that a more experienced cook might rearrange, adapt and refine recipe factsheets. Referring to the earlier Better Homes and Garden Handyman's Book, Goldstein suggests that the book's updatable format reinforces 'notions of individuality and self-sufficiency behind do-it-yourself' (Goldstein 1998: 40). It is difficult to gauge the extent to which readers did indeed update and customise their manuals. However, it is clear that as a publication genre, the DIY manual predicated the notion and processes of individuation; it was intended as a basic guidebook that prompted individual interpretation and the customisation of projects to some degree.

Throughout the manual, there is a discernible shift between prescriptive advice and the encouragement of individual interpretation. Chapter 2 draws further analogies between the processes used to choose colour in interior décor and the assembling of an outfit: "[w]ould you choose a red dress to make you look smaller? It's easy to use the color facts you already know in decorating your home' (Better Homes and Gardens 1961: 19). Subsequent pages encourage readers to apply the same approach they use for coordinating their clothing patterns and textures to the arrangement of household furnishings. In Chapter 11 , readers are also encouraged to consider all aspects of their interiors to ensure a coordinated approach to table décor and dinnerware (Better Homes and Gardens 1961: 338-339). This comprehensive approach to styling all aspects of home and clothing reinforces the sense that individual aesthetic expression relates to the construction of a consistent but individualised identity and persona.
Even so, there is a discernible dichotomy and tension between the conflicting notions of individualism and social conformity that are communicated in the decorating advice, which privileges certain aesthetic decisions. For example, the manual suggests that certain accessorising techniques could be classified as 'right' or 'wrong' when applied to the scenario of side table decoration (Better Homes and Gardens 1961: 278-279). One is left wondering if such didactic judgments are at odds with the initial suggestion that individual expression is valid: '[i]t's your home, what kind do you want?' (Better Homes and Gardens 1961: 7). The freedom to construct one's individual identity through aesthetic self-expression appears to be tempered by a conflicting desire for conformity with social norms and styles associated with the family types outlined in the manual. Regardless, there is a consistent though implicit link between DIY action and the construction of social identity (conformist or otherwise) throughout the manual.

\section{The formation of countercultural identity and the DIY manual}

By the late 1960s and into the 1970s, the emergence of an alternative, North American cultural identity was evident in the variety of DIY manuals targeted at a dispersed countercultural audience, many living within rural communes. Andrew Kirk, a historian of the counterculture, argues that these manuals emerged from a new publishing culture of the 1960s and 1970s that had a DIY ethos at its core and was geared to a 'do-it-yourself-obsessed generation' (Kirk 2007: 5). One of the most well-known-and now wellresearched-of the countercultural DIY manuals is Stewart Brand's Whole Earth Catalog (WEC). The WEC included a vast range of products and information on topics as varied as education, religion, child-rearing, architecture, and building construction in order to promote a holistic and self-sustaining lifestyle for the individual counterculturalist and his 'extended [countercultural] family' (Ant Farm, in Scott 2008: 70). Felicity Scott, an architectural theorist, argues that the WEC 'fuelled the do-it-yourself ideals of access to tools and information and other strategies for withdrawing from normative lifestyles and capitalist modes of consumption and waste' (Scott 2008: 81). According to Brand, the WEC's format was modelled on another North American retail catalogue-that of L. L. Bean-but was positioned as a radical departure from its commercial intentions. For Brand, the $W E C$ was a 'catalog of goods that owed nothing to the suppliers and everything to the users' (Brand, quoted in Kirk 2007: 1). Regardless of this claim, it could be argued that the WEC reinforced the association of social transformation with DIY action and (selective) consumerism because it nonetheless advertised those books, products, suppliers and services deemed appropriate for the countercultural lifestyle. As argued by Thomas Frank, a critic of North American culture, the images and discourses of the countercultural movement were readily co-opted by industries that saw their members as advocates of 'new understandings of consumption' (Frank 1997: 27). ${ }^{5}$ 
Other countercultural manuals also functioned both as how-to books and advertising catalogues. The Spaghetti City Video Manual: A Guide to Use, Repair, and Maintenance (1973) is based on Sony portable video recording products and, alongside its instructional information, includes a list of Sony products in its epilogue (Videofreex 1973: 108-111). The now-defunct art and architecture collective Ant Farm also produced their own manual for DIY inflatables-the Inflatocookbook (1970 and 1973), which refers to several products and suppliers, including an extract from the 'Venturi-Frame Exhausts Fan Kits' supplier catalogue (Ant Farm 1970, 1973: 'Air Supply'); a reference to an auger supplier, A. B. Chance Co, from New Brunswick ('Anchoring'); and a summary of other inflatable makers alongside general material suppliers ('Fantasy'). Ant Farm does, however, encourage its readers to use readily available items such as recycled fans (Ant Farm 1970, 1973: 'Air Supply'). It is worth noting that the earlier DIY manuals like Fifty Things to Make for the Home and the Better Homes and Gardens Decorating Book did not contain explicit references to commercial suppliers (even if the monthly Better Homes and Gardens magazine did); and thus by comparison, some of the countercultural manuals could be seen to 'owe' as much if not more to consumerism than the early post-Depression guidebooks. ${ }^{6}$

Using passionate and often pointed language, the countercultural publications were positioned as much more direct tools for social and ideological transformation than the earlier DIY manuals and discourse. The editors of WEC used emphatic language to communicate the Catalog's radical social agenda: 'introducing world-changers to world-changing tools' (Rheingold 1994: cover insert). Brand himself declared that it was intended as a comprehensive guidebook for citizenry: '[a] theory of civilization is inherent in the Whole Earth Catalog' (Brand 1994: 5). In an equally trenchant example, the preface of the 1976 Radical Technology manual likewise begins with a passionate humanitarian plea:

This is a book about technologies that could help create a less oppressive and more fulfilling society. It argues for the growth of small-scale techniques suitable for use by individuals and communities, in a wider social context of humanised production under workers' and consumers' control. (Harper, Boyle and the Editors of Undercurrents 1976: 5)

As such, Radical Technology could be positioned as part of the broader countercultural interest in the reappropriation of technologies for autonomous living and self-built housing. Fred Turner, a theorist of the counterculture, argues that publications and manuals like these (and particularly the WEC) promoted the idea that the products of American science and industry-from camping gear to calculators-could be reconfigured as small-scale devices essential to individual collective transformation' (Turner 2006: 94). The intention of Radical Technology's editors to humanise technology and improve society was declared explicitly in its preface: 'we have tried to express the social contexts of Radical Technology, situations which, although they may look utopian, really could be implemented now if sufficiently large groups of people got themselves together' (Harper, Boyle and the Editors of Undercurrents 1976: 5). They argue that changes in lifestyle enacted at a residential scale can have a broader impact on systems of production and consumption inflecting society as a whole. Thus small-scale technologies are positioned as supporting an alternative mode of living to that of 'modern capitalist societies [which] are morally contemptible, ruthlessly exploitative, ecologically bankrupt' (Harper, Boyle and the Editors of Undercurrents 1976: 5, 6).

Radical Technology is not specifically intended as a straightforward 'recipe book', but it does include some detailed instructional information to encourage DIY activity (Harper, Boyle and the Editors of Undercurrents 1976: 5). The preface, introduction and a section called 'Other Perspectives' all introduce the book's focus on small-scale technologies that can be readily used for self-initiated projects and the creation of alternative lifestyles. A further six themed sections present information on topics including: 'Food', 'Energy, 'Shelter', 'Autonomy', 'Materials', and 'Communications'. The 'Autonomy' section contains several pages dedicated to designs for houses with reduced reliance on centralised power grids, including projects by architects Alexander Pike, Brenda Vale and others drawn from the Autonomous Housing Study at the Department of Architecture of the University of Cambridge (Harper, Boyle and the Editors of Undercurrents 1976: 150-151). Autonomous living is seen to have a positive impact on social cohesion: 'Far from the separatism of some of its adherents, technical autonomy can contribute to the well-being of the wider society: Co-operative autonomy' (Harper, Boyle and the Editors of Undercurrents 1976: 136). A brief section under the theme of 'Shelter' further argues for the transformative social effects of selfproduced spaces called 'Inflatables', inflated structures made of plastic sheets or bags which are heat-seamed and taped together. The written text is accompanied by four images of inflatables of different scales, with one occupied by a person. Somewhat at odds with the evident ecological focus of Radical Technology-and even though they require a 'power source and fans to keep them blown up' (Harper, Boyle and the Editors of Undercurrents 1976: 105)-inflatables are also therein referred to as potential long-term housing. More specifically, inflatables are seen as appropriate tools of collective social experimentation: '[m] ost exciting use of inflatables (eg. Action Space) is not as dwellings but as people-mixers and mindblowers [...] The effect these have on rolling crowds is dynamic to say the least [...] People attempt to walk, slither, crawl, bounce, float, roll, sink into and over them' (Harper, Boyle and the Editors of Undercurrents 1976: 105). Radical Technology posits a variety of experimental uses for inflatables, including 'air rafts and island kites, solar powered airships, big sex dolls, helium UFO's, you name it' (Harper, Boyle and the Editors of Undercurrents 1976: 105). The amorphous and dynamic character of the plastic envelope seems to 
reinforce the social identity of the occupants as similarly fluid and indeterminate.

Interestingly, Radical Technology does not contain any detailed instructions for inflatable construction and makes no reference to Ant Farm's earlier self-produced DIY manual, Inflatocookbook (1970 and 1973)-nor its video companion, Inflatables Illustrated (1971). These Ant Farm manuals are nevertheless arguably the precedents for the rationale and social benefits of DIY inflatables invoked in Radical Technology. For Ant Farm, the construction of DIY inflatables served the explicit purpose of collective social experimentation because the unusual and dynamic spatial effects of inflatables that are created through the combination of air and fabric 'unhinge' conventional architectural programmes. Thus inflatables involve 'breaking down people's category walls about each other and their own abilities' (Ant Farm 1970 and 1973: 'A Course in Getting Acquainted with Inflatables'). In a total sensory and bodily encounter with moving fabric, air, tape and other people, Ant Farm claims that inflatables overcome the conceptual and programmatic limitations of standard interiors. Thus the

new dimensional space becomes more or less whatever people decide it is-a temple, a suffocation torture device, a pleasure dome. A conference, party, wedding, meeting, regular Saturday afternoon becomes a festival. (Ant Farm 1970 and 1973: 'A Course in Getting Acquainted with Inflatables')

The original 1970 Inflatocookbook had loose-leaf inserts within a plastic sleeve (fig. 2), reminiscent of the earlier updatable format of the Better Homes and Gardens Decoration Book. This experimental graphic format was intended to prompt exchanges between Ant Farm and its readers, who were encouraged to send in 'feedback' for inclusion in subsequent editions of the Inflatocookbook (Ant Farm 1970: 'Feedback'). The 1973 edition of the Inflatcookbook was permanently bound (though still unpaginated), indicating that the updatable and evolving format may not have been as successful as originally intended (Scott 2008: 66). While the earlier Better Homes and Gardens Decorating Book had an ongoing supply of decorating tips and information through its monthly magazine, the Inflatocookbook was a stand-alone, independent publication, rendering the 'feedback-loop' of the later publication sporadic at best. Although the inflatable typology is suggested as the predecessor of Ant Farm's residential project, The House of the Century (Scott 2008: 139), DIY inflatables had a limited applicability beyond providing temporary experimental enclosure for very select countercultural events and audiences. As shelters for everyday activities, the inflatables had significant problems related to climatic control, wind pressure and tie-down, not to mention the immense consumption of energy involved in powering the fan blower: problems evident when Ant Farm built an inflatable in the Californian Saline Valley desert to temporarily house the production team of WEC's 1970 Whole Earth Catalog Supplement (Scott 2008: 83). Of greater interest here, though, is not the success

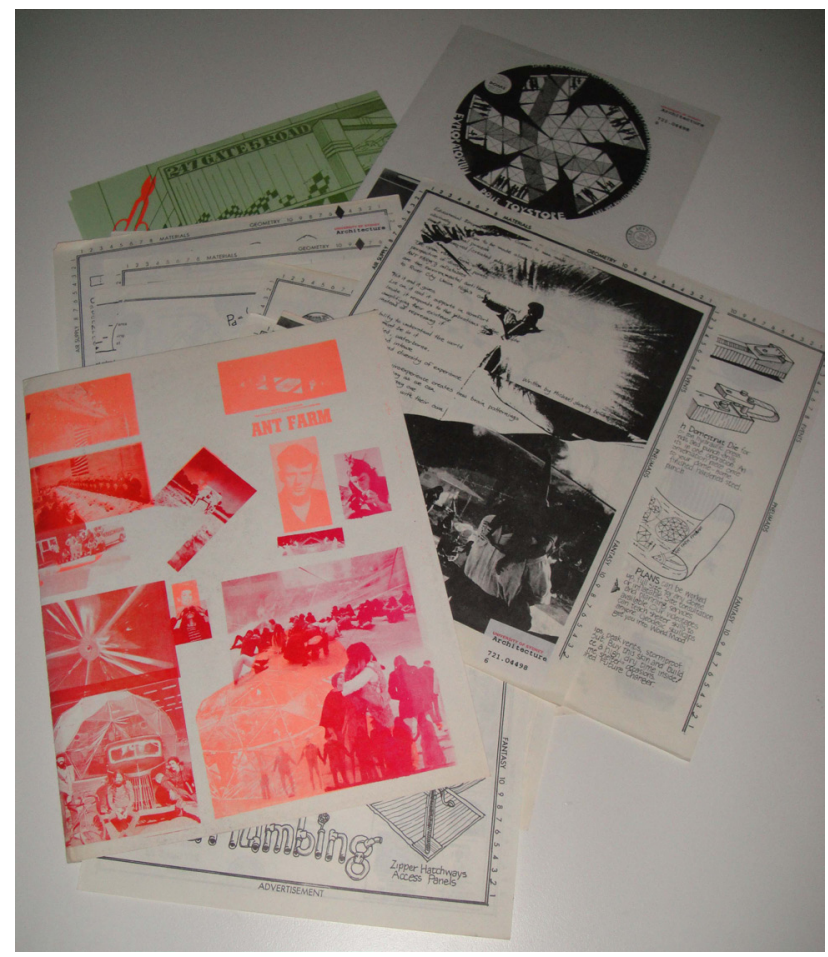

Fig. 2: The 1970 edition of Ant Farm's Inflatocookbook also consisted of loose-leaf inserts originally intended for easy update and replacement. Photograph by the author, 2012.

of inflatables as everyday shelters and transformative mechanisms per se-separate issues in their own rightbut the emphatic connection made between the making of inflatables as a mode of experimental DIY architectures and the social transformation invoked by Radical Technology and Ant Farm in Inflatocookbook and Inflatables Illustrated. Furthermore, Inflatocookbook explicitly associated the production of space and the countercultural self with a form of selective consumerism. It included advertisements for products and material suppliers alongside howto information for the do-it-yourselfer. By referring to the ideological, technical, and product guidance throughout Inflatocookbook, the counterculturalist could become a producer not only of space, but of the self:

He takes what he needs from different places, producing only one thing: HIMSELF, a system resource center for creating tools to solve any problem. Where he is going is where he is at. (Ant Farm 1970 and 1973: 'Good Taste Page: Pneumatics')

\section{The DIY manual and ethos as a mode of social transformation}

As a notion and as a term, DIY culture emerged in close association with the DIY manual following the Great Depression era in North America. The manual became an important educational platform for disseminating how-to information and its underpinning ideologies whilst simultaneously conflating DIY action with social transformation. The early DIY manuals examined in this paper generally focused on small-scale projects within private residential environments, but this in itself did not delimit the impact 
of DIY activities to the residential sphere alone. Indeed, DIY was seen to transform not only the home interior but the social persona of the do-it-yourselfer and his or her family. There is also value in reading across the history of the DIY manual from the 1940s to the 1970s because this challenges something of the specificity of the countercultural movement. Rather than seeing the countercultural manual and its attendant DIY ethos as intrinsic to a singular ideology, it involved the appropriation of practices and an innate consumerism already present in the earlier DIY manuals on which they drew. There are also discernible differences and similarities between the early manuals of the 1940s and 1950s and the later countercultural DIY manuals of the 1960s and 1970s, and even between different manuals of the same time periods. These comparative differences do not diminish the argued connection between DIY and social transformation, but rather indicate differently nuanced associations between identity, productivity and consumerism. The earlier manuals and DIY discourse of the 1940s and 1950s generally invoke a subtle connection between the construction of home and family, using descriptive words and images to link productivity with the coherence of the family unit. In contrast, the countercultural manuals used strong ideological and somewhat lyrical language to justify and promote DIY.

Countercultural manuals such as the WEC and Inflatocookbook functioned simultaneously as both educational tools and advertising catalogues for select, ecologically appropriate goods and suppliers. Accordingly, one might suggest that these countercultural DIY manuals served not only to confirm the inextricable relation between DIY action and social transformation, but to extend this relation to the forces of consumerism-however ecologically appropriate this consumerism might have been. A focus on, and interest in, artisanal skills and small-scale production methodologies notably offers a line with which to connect such apparently disparate publications as the 1941 Fifty Things to Make for the Home and the 1976 Radical Technology. Indeed, these manuals did not go so far as to advertise particular goods and services in the same manner as the WEC and Inflatocookbook countercultural publications, which indicate the growth of consumerist forces in all facets of society.

Detailed examination of both the early and later countercultural phase DIY manuals also confirms that regardless of ideological or social difference, DIY was linked to the transformation of the self (individual and / or collective): be it the individual husband-handyman escaping his desk-bound office pressures; the nuclear family united in homemaking; or the alternative countercultural family bonded through communal life and self-production. In Roland's words, DIY 'cuts across income brackets, educational levels, social distinctions' (Roland 1958: 154). While the countercultural manual may be positioned as a radical co-option of the mainstream retail catalogue format, it might equally be understood as an extension of the ideology of self-transformation already established by the DIY manuals and catalogues of the 1940s and 1950s. The countercultural manuals encouraged a comprehensive mode of living through knowledge, information, products and action, in the same way that the early DIY manuals associated DIY action and productivity with the life of the American nuclear family. From its inception, the DIY manual functioned as a tool for aligning self-directed action and productivity with comprehensive ideological positions-mainstream and alternative alike. It may be difficult, if not impossible, to evaluate the extent of social transformation attributable to specific DIY initiatives and manuals. Even so, the broader value of any DIY action may indeed reside in its perceived mediation between the production of the self and that of the society to which the individual belongs.

\section{Notes}

${ }^{1}$ Architectural historians Felicity Scott, Simon Sadler, Caroline Maniaque-Benton and Larry Busbea have written extensively on the architects of the countercultural period. Some of the material of the present paper is also an extension of research conducted for the author's PhD.

2 The projects contained in the manuals under discussion are generally residential, with the exception of the video and temporary inflatable projects invoked in specific countercultural manuals, including Videofreex's The Spaghetti City Video Manual (1973); Ant Farm's Inflatocookbook (1970, 1973); and Harper, Boyle and the editors of Undercurrents' Radical Technology (1976). The aforementioned projects occur within manuals that also feature or refer to residential projects.

${ }^{3}$ Gelber refers to an article by Garrett Winslow titled 'Practical Decoration for the Home Interior', Suburban Life, 15 (Oct. 1912).

${ }^{4}$ Roland is referring to the 1954 article on DIY in the Time magazine (63).

${ }^{5}$ Frank also invokes a former editor of the WEC, Art Kleiner, who has explicitly connected the counterculture to the emerging business management theory of this time (Frank 1997:26).

${ }^{6}$ The link between the counterculture, consumerism and product advertising in post-war North America is also argued by Frank in his 1997 text The Conquest of Cool.

\section{References}

Ant Farm 1970 Inflatocookbook. San Francisco: Ant Farm Inc., November10-December 10.

Ant Farm 1973 Inflatocookbook. San Francisco: Ant Corps, Second Edition, July.

Ant Farm 2003 Inflatables Illustrated. In: Lord, C Ant Farm Video. Ant Farm, colour and B\&W NTSC DVD, 23 min. Originally published in 1971.

Better Homes and Gardens 1961 Better Homes and Gardens Decorating Book. Des Moines, Iowa: Meredith Publishing Company.

Brand, S 1994 Front Matter: Foreword: Civilisation and Its Contents. In: Reinngold, $\mathrm{H}$ The Millenium Whole Earth Catalog. San Francisco: Harper San Francisco, p. 5.

Frank, T 1997 The Conquest of Cool: Business Culture, Counterculture, and the Rise of Hip Consumerism. Chicago: 
The University of Chicago Press. DOI: http://dx.doi. org/10.7208/chicago/9780226924632.001.0001

Gelber, S M 1999 Hobbies: Leisure and the Culture of Work in America. New York: Columbia University Press.

Goldstein, C 1998 Do It Yourself: Home Improvement in $20^{\text {th }}$ Century America. Washington and New York: National Building Museum, Washington and Princeton Architectural Press.

Harper, P, Boyle, $\mathbf{G}$ and the editors of Undercurrents (eds) 1976 Radical Technology. New York: Pantheon Books.

House Beautiful 1954 What not to do yourself. House Beautiful, 96, July, pp. 54 and 108.

Kirk, A 2007 Counterculture Green: The Whole Earth Catalog and American Environmentalism. Lawrence: University of Kansas Press.

Rheingold, H (ed.) 1994 Untitled introduction. In: The Millenium Whole Earth Catalog. San Francisco: Harper San Francisco, cover inset.

Roland, A 1958 Do-It-Yourself: A Walden for the Millions? American Quarterly, 10, 2, Part 1 (Summer 1958), pp. 154-164.

Scott, F D 2008 Living Archive 7: Ant Farm Allegorical Time Warp: The Media Fallout of July 21, 1969. Barcelona: Acta.
Smith, C D 2012 Productive Matters: the DIY Architecture Manuals of Ant Farm and Paolo Soleri. Doctoral thesis. Sydney: Faculty of Architecture, Design and Planning, University of Sydney.

Starr, J Jr. 1941 Fifty Things to Make for the Home. New York: Whittlesey House, McGraw-Hill Book Company, Inc.

The Museum of Modern Art 1951. '90751-49'. Untitled Media release. Available at http://www. moma.org/docs/press_archives/1541/releases/ MOMA_1951_0059_1951-09-07_90751-49.pdf?2010 [Last accessed 06/09/2013].

Time 1954 Do-It-Yourself: The New Billion-dollar Hobby. Time, Pacific edition, Business: Modern Living, August 2, pp. 46-51.

Turner, F 2006 From Counterculture to Cyberculture: Stewart Brand, the Whole Earth Network, and The Rise of Digital Utopianism. Chicago: The University of Chicago. DOI: http://dx.doi.org/10.7208/chicago/ 9780226817439.001.0001

Videofreex 1973 The Spaghetti City Video Manual: A Guide to Use, Repair, and Maintenance. New York: Praeger Publishers.

WEC 1971 The Last Whole Earth Catalog: Access to Tools. San Francisco, Harmondsworth: Portola Institute, Penguin Books Ltd.

How to cite this article: Smith, C 2014 Handymen, Hippies and Healing: Social Transformation through the DIY Movement (1940s to 1970s) in North America. Architectural Histories, 2(1): 2, pp. 1-10, DOI: http://dx.doi.org/10.5334/ah.bd

Published: 19 March 2014

Copyright: (c) 2014 The Author(s). This is an open-access article distributed under the terms of the Creative Commons Attribution 3.0 Unported License (CC-BY 3.0), which permits unrestricted use, distribution, and reproduction in any medium, provided the original author and source are credited. See http://creativecommons.org/licenses/by/3.0/.

] $\mathrm{u}[\quad$ Architectural Histories is a peer-reviewed open access journal published by Ubiquity Press. 